Pediat. Res. 4: 55-62 (1970)

Aspartate embryogenesis

transcarbamylase pyrimidine biosynthesis

dihydro-orotase uridine kinase

\title{
Biosynthesis of Pyrimidines by Various Organs of the Chick During Embryogenesis
}

\author{
Alberto Galofré and Norman Kretahmer ${ }^{[55]}$ \\ Lt. J.P. Kennedy, Jr. Laboratories for Molecular Medicine, Department of Pediatrics, \\ Stanford University School of Medicine, Stanford, California, USA
}

\begin{abstract}
Extract
Activities of two enzymes of the de novo pyrimidine biosynthetic pathway, aspartate transcarbamylase and dihydro-orotase, and one enzyme of the salvage pathway, uridine kinase, were assayed in the liver, heart, brain, and intestine during embryogenesis of the chick, to assess the relation of these pathways to cellular proliferation and organ growth. As the period of embryogenesis ended, the increment of cellular proliferation, as determined by changes in amount of DNA, of liver, brain, and heart decreased, while that of intestine remained relatively constant. The most elevated activities for both enzymes of the de novo pathway were observed in the earliest stages of development, decreasing thereafter with age. These two enzymatic activities changed synchronously in each of the tissues studied. In each organ, the highest activities of the de novo pyrimidine biosynthetic enzymes were coordinated with the stage of most rapid rate of cellular proliferation. In addition, the enzymatic patterns during development paralleled the overall growth rates of different organs. The activity of uridine kinase increased throughout embryonic development in the organs investigated, in contrast to the activities of the enzymes of the pathway of de novo pyrimidine biosynthesis.
\end{abstract}

\section{Speculation}

The de novo pyrimidine pathway might be the prime source of pyrimidines at early stages of development when macromolecules must be assembled from simple precursors. As the embryo grows, the use of available preformed material would be a more efficient means for synthesis of nucleotides.

Introduction

Previous work in this laboratory $[19,26]$ and that of others $[2,18]$ has shown that the activity of aspartate transcarbamylase, one of the enzymes of pyrimidine biosynthesis, was considerably elevated in liver and heart of the fetal rat compared with adult tissues. With the use of radioactive precursors it was observed [20] that carbamylaspartate could be readily converted to orotate, and orotate to UMP by liver and heart of the fetal rat. This synthetic activity, in the tissues of the fetal rat, was diminished in adult liver and almost absent in preparations of adult heart. These observations impelled us to examine more closely the activities of those enzymes responsible for the biosynthesis of pyrimidines, particularly in relation to the growth of different embryonic tissues.

Present knowledge indicates that pyrimidine biosynthesis in fetal or embryonic tissues probably proceeds as follows: 1) glutamine, as the possible nitrogen 
source $[15,24]$, bicarbonate, and adenosine triphosphate (ATP) react to form carbamyl phosphate; this step is catalyzed by carbamyl phosphate synthetase; 2) carbamyl phosphate reacts with aspartate to form carbamylaspartate by the action of aspartate transcarbamylase; 3) ring closure is accomplished by dehydration yielding dihydro-orotate through the action of dihydro-orotase; 4) dihydro-orotate is oxidized to orotate in the presence of dihydro-orotate dehydrogenase; and 5) orotate is converted to orotidine-5-phosphate and then to uridine monophosphate (UMP).

Pyrimidine nucleotides can also be synthesized from preformed bases by the salvage pathway [28]. We have investigated the activities of certain enzymes of the de novo biosynthetic pathway and the formation of phosphorylated uridine from uridine to assess the relative importance of each pathway during embryogenesis. The action of these enzymes provides precursors for nucleic acid synthesis, and consequently, may change in relation to cellular proliferation and growth.

In the present study, the chick embryo was used because of the relative ease in determining the definite stages of embryogenesis [16, 29, 30] and because observations could be made at very early stages of development of various organs. Also, the chick embryo has the advantage of being uricotelic, and thus does not have a functioning urea cycle that would also utilize carbamyl phosphate, an intermediate common to the pathways for urea and pyrimidine biosynthesis [17].

\section{Materials and Methods}

White Leghorn chick embryos of the same strain (G-813) were used throughout these experiments; they were purchased [42] at the desired stage of development. For some experiments, fertilized eggs were incubated in our laboratory at $38^{\circ}$ at $40-70 \%$ humidity. After hatching, the chicks were given water, but no food. Stages of development were judged according to the recommendations of HAMBURGER and HAMILTON [16]. Embryos and chicks were decapitated.

\section{Analytical Procedures}

Liver, heart, brain, and intestine were removed quickly and chilled; determinations of enzymatic activity in pooled tissues were done on the same day. Unless otherwise indicated, a 20\% homogenate was made in $0.25 \mathrm{M}$ sucrose with a Potter-Elvehjem glass homogenizer. The homogenate was centrifuged at $10,000 \times g$ for $10 \mathrm{~min}$ in a centrifuge [43] and the supernatant fluid then was used for enzymatic analyses. In all cases studied, formation of product was directly proportional to amount of supernatant fluid and was linear with respect to the time of incubation. Enzymatic activities were assayed in each case at the apparent pH optimum.

Aspartate transcarbamylase. Carbamoyl phosphate: L-aspartate carbamoyl transferase (EC.2.1.3.2) was measured by the method of Gerhart and PARDEE [13] that determines production of a carbamyl aspartate chromophore.

The assay mixture contained: (in $\mu$ moles) carbamyl phosphate, 4; aspartate, 20; diethanolamine buffer, pH 9.2, 100; and supernatant fluid, $0.2 \mathrm{ml}$, in a total volume of $1.0 \mathrm{ml}$. This mixture was incubated in a water bath at $37^{\circ}$ for $30 \mathrm{~min}$ and the reaction stopped with $1.0 \mathrm{ml}$ of $0.5 \mathrm{M}$ perchloric acid. The perchlorate was removed by precipitation with saturated $\mathrm{KOH}$ and, following centrifugation, $0.5 \mathrm{ml}$ of supernatant fluid was used for assay.

Dihydro-orotase. L-4,5-Dihydro-orotate amino hydrolase (EC.3.5.2.3) was determined by the method of Bresnick and Hrtauings [3]. Dihydro-orotate, formed from carbamylaspartate, was treated with strong alkali [1] and the rate of decrease of absorbancy at $240 \mathrm{~m} \mu$ was measured with a recording spectrophotometer [44]. The incubation mixture contained 16 $\mu$ moles carbamylaspartate; $200 \mu$ moles $\mathrm{Na}$ phosphate buffer, $\mathrm{pH} 6.5$; and $0.2 \mathrm{ml}$ supernatant fluid in a total volume of $3.0 \mathrm{ml}$, and was incubated at $37^{\circ}$ for $60 \mathrm{~min}$; the reaction was stopped with $0.2 \mathrm{ml}$ of $4 \mathrm{~m}$ perchloric acid.

Uridine kinase. Adenosine triphosphate: uridine 5'phosphotransferase (EC.2.7.1.48). A $5 \%$ homogenate was made in cold $0.05 \mathrm{M}$ tris (hydroxymethyl) amino methane-1,3-propanediol (Tris) buffer, pH 7.4, and centrifuged at $48,000 \times g$ for $1 \mathrm{~h}$ in a centrifuge [43]. The supernatant fluid was used for analysis. Activity of uridine kinase was measured by a modification of the method of SköLD [34, 35]. The incubation mixture contained: (in $\mu$ moles) ATP, $15 ; \mathrm{MgCl}_{2}, 10$; Tris buffer, $\mathrm{pH} 7.4,10$; and uridine-2 $\left[{ }^{1 s} \mathrm{G}\right], 0.01 \mu \mathrm{Ci}$ (specific activity, $30 \mu \mathrm{Ci} / \mu \mathrm{mole}$ ) [45], and supernatant fluid, $0.2 \mathrm{ml}$, in a final volume of $0.6 \mathrm{ml}$. The mixture was incubated for $15 \mathrm{~min}$ at $37^{\circ}$ and the reaction stopped by placing the tubes in a boiling water bath for $1 \mathrm{~min}$. After centrifugation, $200 \mu \mathrm{l}$ of supernatant were applied to strips of Whatman no. $3 \mathrm{MM}$ paper and were chromatographed overnight in 2-propanolacetic acid-water, 6:3:1. The strips were cut into $2.5-\mathrm{cm}$ portions and placed in vials with $10 \mathrm{ml}$ of scintillation counting fluid ( $5 \mathrm{~g} /$ liter of 2,5-diphenyloxazole [PPO], and $0.5 \mathrm{~g} /$ liter of $p$-bis-[2-(5-phenyloxazolyl)]-benzene [POPOP], in toluene) and counted in a liquid scintillation spectrometer [46]. The number of counts found in the areas identified as phosphorylated uridine were used as a semiquantitative measure of enzymatic activity. 
Dihydro-orotate dehydrogenase. L-4, 5-Dihydro-orotate: oxygen oxidoreductase (EG.1.3.3.1) and dihydroorotase (EC.3.5.2.3). Activity of these enzymes was measured in the liver of chick embryos by determining the conversion of dihydro-orotate to carbamylaspartate and orotate. The incubated mixture contained: (in $\mu$ moles) $\mathrm{D}, \mathrm{L}-4,5$, dihydro-orotic acid-6 $\left[{ }^{14} \mathrm{C}\right], 2.7$ (specific activity $0.37 \mu \mathrm{Ci} / \mu$ mole); Tris buffer, $\mathrm{pH} 8.0$ (at $37^{\circ}$ ), 10; and $20 \%$ whole homogenate, $0.4 \mathrm{ml}$, in a total volume of $1.0 \mathrm{ml}$; it was incubated at $37^{\circ}$ for $1 \mathrm{~h}$. The reaction was stopped with $0.2 \mathrm{ml}$ of $20 \%$ trichloroacetic acid. After extraction of the acid with ether, a 50- $\mu 1$ aliquot of deproteinized supernatant fluid was placed on thin-layer DEAE-cellulose plates and chromatographed overnight, as described by SHAFrITZ and Senior [31]. The chromatograms were scanned with a radiochromatogram scanner [47]. Two-centimeter portions were then scraped into vials containing $10 \mathrm{ml}$ of scintillation fluid and counted in a scintillation spectrometer [46]. The number of counts found in the area identified as carbamylaspartate and orotate was used as an indication of enzyme activity. No further studies were attempted with this system since the reaction can go either toward carbamylaspartate or orotic acid, making an accurate analysis of the enzymatic pattern very difficult. Protein was determined by the method of LowRy et al. [23], DNA was extracted by the method of SCHNEIDER [33] and determined by the method of BURTON [7] using sperm DNA [48] as a standard.

Results
Enzyme Activities in Tissues
Aspartate transcarbamylase and dihydro-orotase. Activi-

Aspartate transcarbamylase and dihydro-orotase. Activi-
ies of aspartate transcarbamylase and dihydro-orotase were measured in liver, heart, and brain at days 7, 10, 13,16 , and 19 of embryogenesis in the chick embryo. With intestine, the earliest measurements were performed at 10 days of embryonic age since sufficient amounts of tissue could not be obtained from embryos 7 days of age. Enzymatic activities were also measured in these organs 3 days after hatching. The $\mathrm{pH}$ optima for aspartate transcarbamylase was 9.2, for dihydro-orctase, 6.5, in agreement with those found with rat liver [22] and Ehrlich ascites cells [3]. The activities of both enzymes in the four organs are shown in tables I and II and are expressed on the basis of wet weight, amount of protein in the supernatant fluid, and amount of DNA. Particularly with these enzymes, there was no consensus as to the most appropriate form for expression of results. Regardless of the variable, the activities of both enzymes showed similar patterns in that a general decrease in activitiy occurred as embryogenesis proceeded. There were differences, however, between the various tissues. These differences were particularly evident when the enzymatic activities were expressed on the basis of amount of DNA $[49,50]$. In liver and heart, the activity for aspartate transcarbamylase decreased abruptly between days 13 and 16 of embryogenesis, but this circumstance was encountered only in the liver with dihydro-orotase. In the intestine, an abrupt change in activity occurred for both enzymes between days 10 and 13 of embryogenesis. These findings may be correlated with morphologic changes, since after day 13 the liver progresses from an organ with a large amount of hematopoietic tissue to an or-

Table I. Activity of aspartate transcarbamylase in organs of the chick embryo ${ }^{1}$

\begin{tabular}{|c|c|c|c|}
\hline $\begin{array}{l}\text { Age, } \\
\text { days }\end{array}$ & $\begin{array}{c}\mu \text { moles } / g \\
\text { wet } w \mathrm{t}\end{array}$ & $\begin{array}{c}\mu \text { moles } / \mathrm{mg} \\
\text { protein }\end{array}$ & $\begin{array}{c}\mu \text { moles } / \mathrm{mg} \\
\text { DNA }\end{array}$ \\
\hline \multicolumn{4}{|c|}{ Liver } \\
\hline 7 & $75.0 \pm 5.0$ & $0.745 \pm 0.050$ & $36.7 \pm 2.4$ \\
\hline 10 & $84.5 \pm 7.5$ & $0.802 \pm 0.069$ & $43.1 \pm 3.8$ \\
\hline 13 & $80.7 \pm 3.3$ & $0.766 \pm 0.033$ & $42.0 \pm 1.7$ \\
\hline 16 & $62.7 \pm 6.6$ & $0.525 \pm 0.010$ & $29.5 \pm 3.1$ \\
\hline 19 & $46.7 \pm 2.2$ & $0.400 \pm 0.018$ & $24.8 \pm 1.1$ \\
\hline$+3^{2}$ & $9.2 \pm 4.3$ & $0.074 \pm 0.034$ & $3.1 \pm 1.4$ \\
\hline \multicolumn{4}{|c|}{ Heart } \\
\hline 7 & $25.3 \pm 1.8$ & $0.633 \pm 0.050$ & $18.0 \pm 1.2$ \\
\hline 10 & $23.2 \pm 2.4$ & $0.581 \pm 0.062$ & $16.5 \pm 1.7$ \\
\hline 13 & $24.2 \pm 2.7$ & $0.576 \pm 0.064$ & $17.2 \pm 1.9$ \\
\hline 16 & $14.0 \pm 3.5$ & $0.330 \pm 0.065$ & $8.5 \pm 2.1$ \\
\hline 19 & $11.1 \pm 3.7$ & $0.252 \pm 0.084$ & $7.1 \pm 2.3$ \\
\hline$+3^{2}$ & $3.7 \pm 1.7$ & $0.082 \pm 0.038$ & $1.9 \pm 0.9$ \\
\hline \multicolumn{4}{|c|}{ Brain } \\
\hline 7 & $17.2 \pm 3.0$ & $0.466 \pm 0.081$ & $7.4 \pm 1.3$ \\
\hline 10 & $15.0 \pm 1.0$ & $0.305 \pm 0.028$ & $10.8 \pm 0.7$ \\
\hline 13 & $12.3 \pm 3.1$ & $0.265 \pm 0.071$ & $11.3 \pm 2.8$ \\
\hline 16 & $8.2 \pm 2.0$ & $0.165 \pm 0.041$ & $7.8 \pm 1.9$ \\
\hline 19 & $6.3 \pm 1.9$ & $0.127 \pm 0.029$ & $7.5 \pm 1.6$ \\
\hline$+3^{2}$ & $4.0 \pm 0.5$ & $0.072 \pm 0.010$ & $3.1 \pm 0.3$ \\
\hline \multicolumn{4}{|c|}{ Intestine } \\
\hline 10 & $59.3 \pm 10.1$ & $1.020 \pm 0.110$ & $29.8 \pm 3.0$ \\
\hline 13 & $58.6 \pm 9.9$ & $0.770 \pm 0.100$ & $18.4 \pm 2.5$ \\
\hline 16 & $59.7 \pm 11.0$ & $0.720 \pm 0.140$ & $19.9 \pm 3.9$ \\
\hline 19 & $64.6 \pm 9.4$ & $0.770 \pm 0.110$ & $20.9 \pm 3.0$ \\
\hline$+3^{2}$ & $60.0 \pm 10.5$ & $0.630 \pm 0.150$ & $16.1 \pm 3.9$ \\
\hline
\end{tabular}

1 Results are expressed in micromoles of carbamyl aspartic acid formed per hour and are the mean of four determinations \pm sD.

${ }^{2}+3$ refers to 3 days after hatching. 
gan that at day 19 , contains a great deal of glycogen and fat. Histologically, the early intestine has very few villi, whereas after day 10 the villi become more prominent. In the intestine, the activity for both enzymes was maintained from 10 days of embryogenesis until 3 days after hatching.

To compare the activity of both enzymes in different tissues, the developmental patterns of the specific activities of aspartate transcarbamylase and dihydroorotase are shown in figure 1. In general, the highest values of enzymatic activity were found at the earliest

Table II. Activity of dihydro-orotase in organs of the chick embryo ${ }^{1}$

\begin{tabular}{|c|c|c|c|}
\hline $\begin{array}{l}\text { Age, } \\
\text { days }\end{array}$ & $\begin{array}{c}\mu \text { moles/g } \\
\text { wet wt }\end{array}$ & $\begin{array}{c}\mu \text { moles } / \mathrm{mg} \\
\text { protein }\end{array}$ & $\begin{array}{c}\mu \text { moles } / \mathrm{mg} \\
\text { DNA }\end{array}$ \\
\hline \multicolumn{4}{|c|}{ Liver } \\
\hline 7 & $30.0 \pm 3.6$ & $0.300 \pm 0.036$ & $16.6 \pm 0.5$ \\
\hline 10 & $30.8 \pm 1.8$ & $0.291 \pm 0.018$ & $15.7 \pm 0.9$ \\
\hline 13 & $30.3 \pm 0.6$ & $0.286 \pm 0.006$ & $15.7 \pm 0.3$ \\
\hline 16 & $16.6 \pm 1.1$ & $0.157 \pm 0.008$ & $7.8 \pm 0.5$ \\
\hline 19 & $11.2 \pm 1.9$ & $0.093 \pm 0.016$ & $5.9 \pm 1.0$ \\
\hline$+3^{2}$ & $7.0 \pm 1.2$ & $0.055 \pm 0.009$ & $2.3 \pm 0.4$ \\
\hline \multicolumn{4}{|c|}{ Heart } \\
\hline 7 & $8.3 \pm 0.6$ & $0.202 \pm 0.015$ & $5.9 \pm 0.4$ \\
\hline 10 & $5.9 \pm 0.3$ & $0.143 \pm 0.008$ & $4.2 \pm 0.2$ \\
\hline 13 & $4.7 \pm 0.2$ & $0.110 \pm 0.004$ & $3.3 \pm 0.1$ \\
\hline 16 & $5.0 \pm 0.4$ & $0.111 \pm 0.010$ & $3.0 \pm 0.2$ \\
\hline 19 & $3.3 \pm 0.3$ & $0.073 \pm 0.007$ & $2.1 \pm 0.2$ \\
\hline$+3^{2}$ & $1.6 \pm 0.3$ & $0.036 \pm 0.007$ & $0.8 \pm 0.1$ \\
\hline \multicolumn{4}{|c|}{ Brain } \\
\hline 7 & $7.0 \pm 2.1$ & $0.199 \pm 0.030$ & $3.1 \pm 0.9$ \\
\hline 10 & $5.3 \pm 0.5$ & $0.104 \pm 0.009$ & $3.8 \pm 0.3$ \\
\hline 13 & $5.3 \pm 1.2$ & $0.104 \pm 0.024$ & $4.9 \pm 1.1$ \\
\hline 16 & $4.7 \pm 0.2$ & $0.092 \pm 0.003$ & $4.5 \pm 0.1$ \\
\hline 19 & $3.2 \pm 0.1$ & $0.063 \pm 0.003$ & $3.8 \pm 0.1$ \\
\hline$+3^{2}$ & $2.2 \pm 0.4$ & $0.040 \pm 0.008$ & $1.7 \pm 0.3$ \\
\hline \multicolumn{4}{|c|}{ Intestine } \\
\hline 10 & $17.5 \pm 1.2$ & $0.351 \pm 0.025$ & $10.3 \pm 0.7$ \\
\hline 13 & $14.9 \pm 1.9$ & $0.204 \pm 0.036$ & $5.4 \pm 0.6$ \\
\hline 16 & $15.6 \pm 1.3$ & $0.219 \pm 0.014$ & $6.2 \pm 0.5$ \\
\hline 19 & $15.4 \pm 1.9$ & $0.215 \pm 0.028$ & $5.7 \pm 0.7$ \\
\hline$+3^{2}$ & $15.6 \pm 1.3$ & $0.198 \pm 0.021$ & $4.2 \pm 0.3$ \\
\hline
\end{tabular}

${ }_{1}^{1}$ Results are expressed in micromoles of dihydro-orotic acid formed per hour and are the mean of four determination \pm SD

$2+3$ refers to 3 days after hatching. stages of development. In liver, brain, and heart, these values decreased 5 - to 10 -fold by 3 days after hatching, while the activity of the enzymes in intestine remained stable from 13 days of embryogenesis onward. There

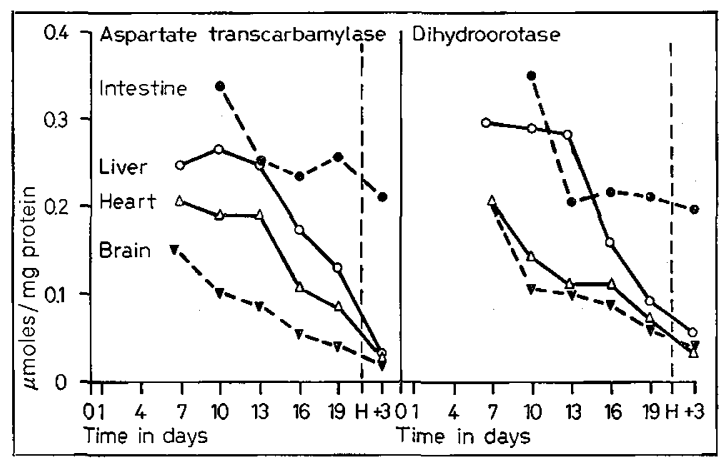

Fig.1. Aspartate transcarbamylase and dihydroorotase in intestine, liver, heart, and brain of the chick embryo. The ' $\mathrm{H}$ ' indicates time of hatching. Incubation time is $20 \mathrm{~min}$ for aspartate transcarbamylase, and $60 \mathrm{~min}$ for dihydro-orotase.

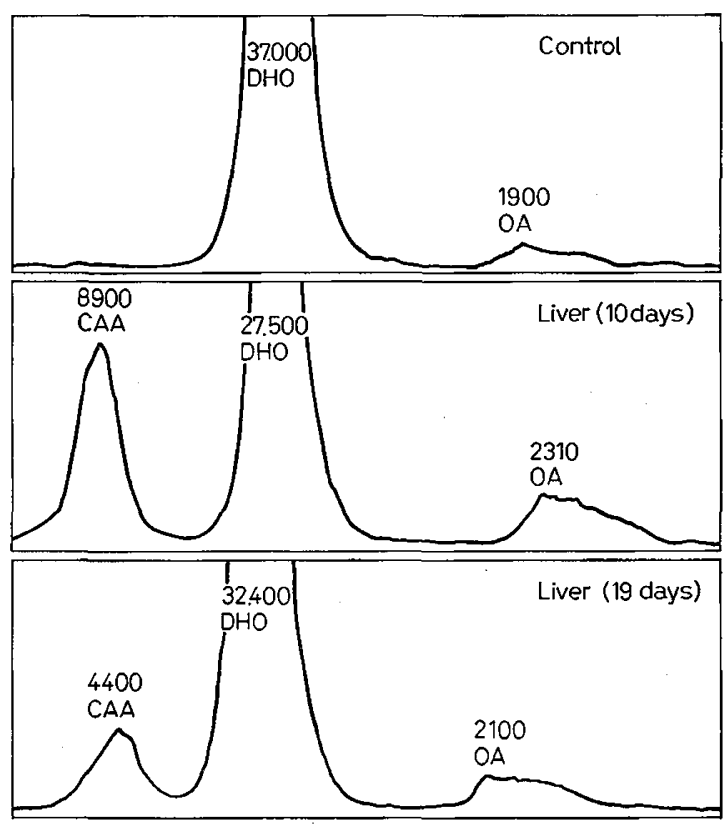

Fig.2. Production of carbamylaspartate and orotate from dihydro-orotate by embryonic chick liver. The peaks represent the content of labeled pyrimidine precursors on the thin-layer chromatograms. The numbers indicate the total counts per minute found within each peak. It is evident that the substrate has a small percentage of orotate as impurity. CAA, carbamylaspartate; DHO, dihydro-orotate; OA, orotate. 
was a great similarity of the developmental patterns for activity of aspartate transcarbamylase and dihydroorotase in liver, brain, heart, and intestine. This finding was similar to that observed by KRETCHMER et al. [19] using whole homogenates of heart and liver.

To ascertain whether the changes in activity observed with age were due to the presence of an inhibitor or activator, mixing experiments were performed. Additions of supernatant fluid derived from liver and heart of 10-day-old embryos were added to supernatant fluids from liver and heart of 19-day-old embryos, respectively. The mixed enzyme preparations of younger plus older fractions yielded activities that were additive. These results suggest the absence of inhibitors or activators.

Dihydro-orotate dehydrogenase and dihydro-orotase. Figure 2 shows a typical experiment indicating conversion of dihydro-orotate to carbamylaspartate and orotic acid. There was more production of carbamylaspartate by the liver of the 10-day-old embryo than that of the 19-day-old embryo. The results with orotate, however, are difficult to interpret. Results obtained with preparations from 13- and 16-day-old embryos were intermediate between those depicted in figure 2 . These data can only be considered as semiquantitative.

Uridine kinase. The developmental patterns of the activity of uridine kinase (fig. 3) for the four organs

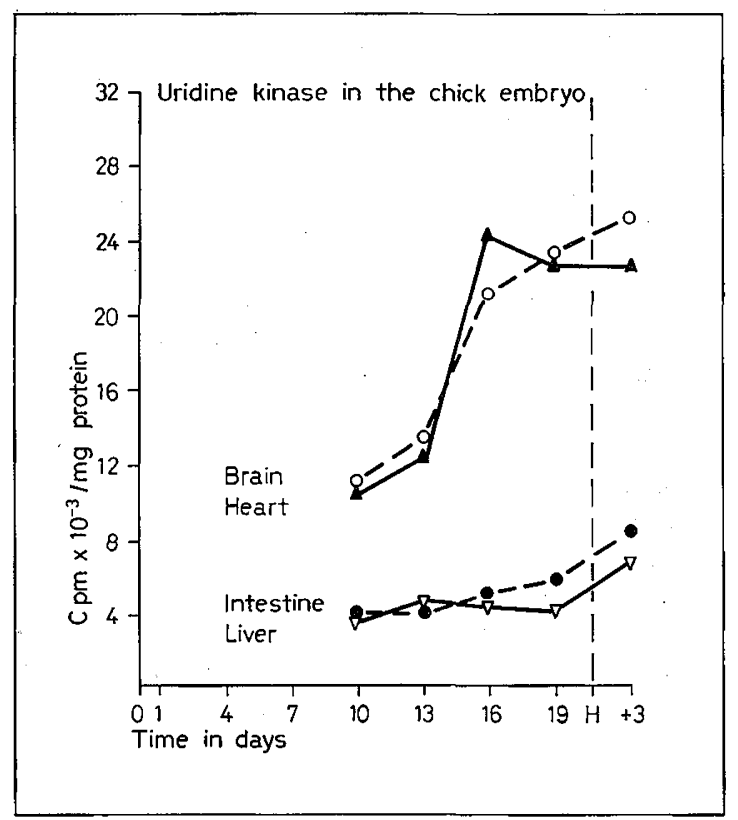

Fig.3. Developmental pattern of uridine kinase in the intestine, liver, heart, and brain of the chick embryo. The ' $\mathrm{H}$ ' indicates time of hatching. during embryogenesis were the converse of those encountered with the enzymes associated with de novo pyrimidine biosynthesis. In contrast to the de novo pathway, the activity for this enzyme was higher in brain and heart than it was in the intestine or liver.

\section{Cellular Growth}

Because of the presumed relation of pyrimidine biosynthesis to cellular proliferation it seemed appropriate to study some variables of growth in the different organs. There was a remarkable increase in the number of cells in each organ (fig. 4). Toward the end of the period of embryogenesis the rates of cellular proliferation of liver, brain, and heart decreased, but during the embryonic periods studied the increment of intestinal DNA was relatively constant. During this growth phase there was a continuous increase of protein per nucleus in liver, heart, and brain whereas in the intestine, this ratio remained constant (fig. 5). The greatest rate of increase in protein was noted in the brain.

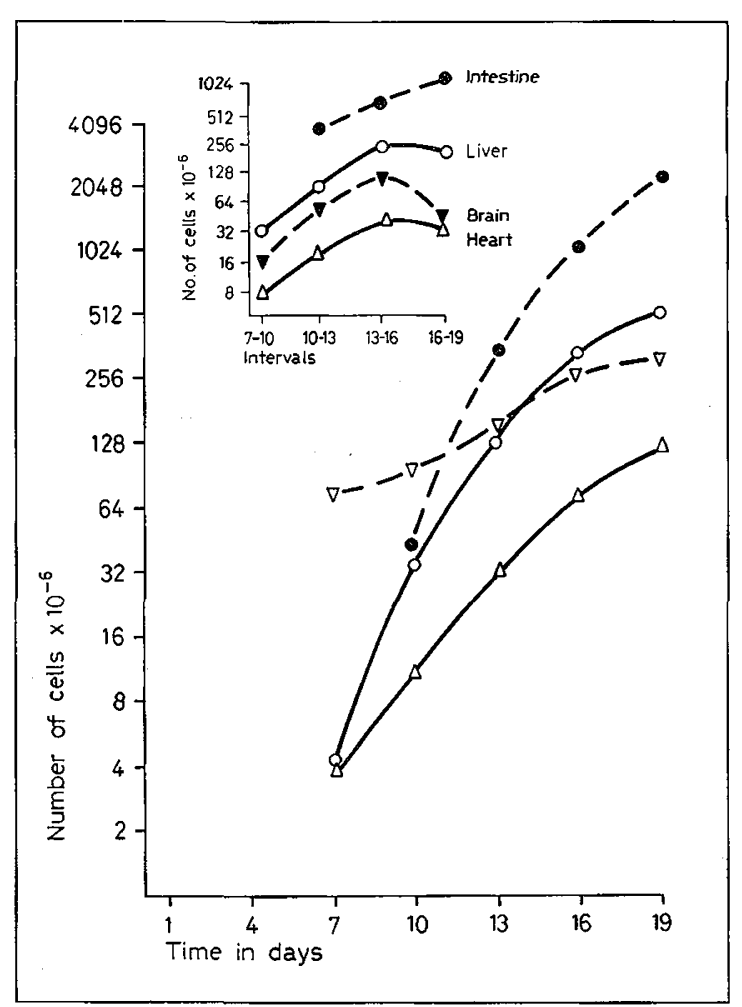

Fig.4. Number of cells per organ as determined by DNA, in liver, heart, brain, and intestine during embryonic development of the chick. Calculations according to ENESCO and LEBLOND [12]. Insert shows absolute increase of number of cells per 3-day interval in liver, heart, brain, and intestine of the chick embryo. 


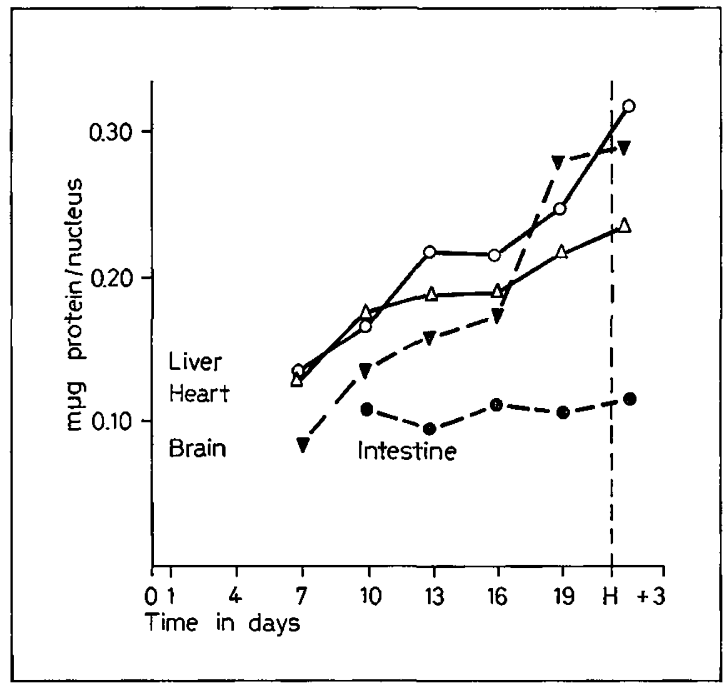

Fig.5. Protein per nucleus in liver, heart, brain, and intestine during embryonic development. The ' $\mathrm{H}$ ' represents time of hatching; calculations as in ENESCO and LeBLono [12].

\section{Discussion}

In our studies, activities of the pyrimidine biosynthetic enzymes of the de novo pathway in the chick embryo correlated with rate of cellular proliferation as measured by amount of DNA in the individual organs at different stages of development. LESLIE and DAvidson [21] studied growth of liver, heart, brain, and muscle of the chick embryo; we have obtained similar data, and in addition, included information concerning the intestine.

Stein and CoHen [36], working with plants, indicated that the specific activity of aspartate transcarbamylase was significantly higher in growing portions than in quiescent parts. Elevated activities have been found in other rapidly growing tissues: ascites tumor cells [9], hepatoma nodules and regenerating liver [8], fetal tissues $[2,18,19,26]$, and mammary gland in pregnancy and lactation [38]. Young et al. [41] correlated the activity of aspartate transcarbamylase of different organs in the adult rat to cellular proliferation measured by mitotic index. They showed that organs with frequent mitotic divisions had high enzyme activity. Conversely, SköLD [35] measured uridine kinase of the 'salvage' pathway in several tissues of young adult rats, mice, and rabbits, and found a direct relation between this enzyme and the growth rate of tissues. These observations may indicate that differences in utilization of each pathway exist during development.

The results obtained in the present study during embryogenesis indicated a possible association between the 'salvage' and the de novo pathway, since there was an inverse relation of the two activities. This phenomenon was most evident in those organs of the chick embryo that had the lowest activities of the de novo pathway, heart and brain. It is not known whether this relation is related to the regulation of either or both pathways. The de novo pathway might be the prime source of pyrimidines at early stages of development when macromolecules must be assembled from simple precursors. As the embryo grows, the use of available preformed material would be a more efficient means for synthesis of nucleotides.

Synchronous change in activity for several enzymes of a pathway has been reported in multicellular organisms. Schrmke [32] has shown that the enzymes of urea biosynthesis rise in a coordinate manner when increasing percentages of dietary proteins were fed to rats. BRown et al. [6] showed the simultaneous appearance of enzymes of the urea pathway during amphibian metamorphosis.

In the present study, the developmental patterns and the magnitudes of aspartate transcarbamylase and dihydro-orotase activities were distinctive for most organs studied, although within the individual organ these characteristics were strikingly similar for both enzymes. These synchronous changes of enzymatic activities encountered during embryogenesis were highly suggestive of a group of proteins that were related genetically.

The allosteric regulation of aspartate transcarbamylase in bacterial systems $[13,14]$ is a classic example of its type. This regulation has not been demonstrated in multicellular organisms $[5,10,20,27]$. Unlike the results in bacterial systems $[39,40]$, attempts to repress aspartate transcarbamylase in mammalian systems by elevation of nucleotide pools have been unsuccessful [4]. It is quite likely that regulation of pyrimidine biosynthesis via aspartate transcarbamylase differs in various species, as reported for Escherichia coli [14], lettuce [25], human leukocytes [27], and chick embryo [2]. TAтіBANA and Iто [37], working with the mouse spleen, suggested that a control site for the de novo pathway might be carbamyl phosphate synthetase rather than aspartate transcarbamylase. This hypothesis was based on the selective inhibition of the enzyme by uridine triphosphate (UTP), and the low activity of carbamyl phosphate synthetase compared with aspartate transcarbamylase. Though these data are accumulating, the question of the regulation of the pyrimidine biosynthetic pathway in multicellular organisms still awaits solution. 
Suminary

Activities of two enzymes of pyrimidine biosynthesis, aspartate transcarbamylase and dihydro-orotase, were determined in the liver, intestine, brain, and heart of the chick embryo during development. The data indicate that these de novo pyrimidine biosynthetic enzymes are very active during periods of intense growth in these organs. In the intestine, where growth persists for an extended period of time, the activities of these enzymes are maintained. Uridine kinase, an enzyme concerned with the salvage of pyrimidine skeletons, increases in activity after the de novo pyrimidine biosynthetic pathway has begun to disappear. From these developmental studies it is possible to hypothesize an intimate genetic relation between enzymes of de novo pyrimidine biosynthesis.

\section{References and Notes}

1. Batt, R.D.; Martin, J.K.; Ploeser, J.M. and MURRAY, J. : Chemistry of the dihydropyrimidines. Ultraviolet spectra and alkaline decomposition. J.Amer. chem. Soc. 76: 3663-3665 (1954).

2. BRESNICK, E.: Regulatory control of pyrimidine biosynthesis in mammalian systems; in: G.WEBER: Advances in enzyme regulation, Vol.2., pp.213236 (Macmillan, London 1964).

3. BResnick, E. and Hitchings, G.H. : Feedback control in Ehrlich ascites cells. Cancer Res. 21: 105-109 (1961).

4. Bresnick, E.; Mayfield, E.E. and Mossé, H.: Increased activity of enzymes for the de novo pyrimidine biosynthesis after orotic acid administration. Molec. Pharmacol. 4: 173-180 (1968).

5. BRESNICK, E. and Mossé, H.: Aspartate carbamyl transferase from rat liver. Biochem.J. 101: 63-69 (1966).

6. Brown, G.W.; Brown, W.R. and Cohen, P.P.: Comparative biochemistry of urea synthesis. II. Levels of urea cycle enzymes in metamorphosing Rana catesbeiana tadpoles. J. biol. Chem. 234: 17751780 (1959).

7. Burton, K.: A study of the conditions and mechanism of the diphenylamine reaction for the colorimetric estimation of deoxyribonucleic acid. Biochem.J. 62: 315-323 (1956).

8. Calva, E. and Cohen, P.P.: Carbamyl phosphateaspartate transcarbamylase activity in regenerating rat liver. Cancer Res. 19: 679-683 (1959).

9. Calva, E.; Lowenstern, J.M. and Cohen, P.P.: Carbamyl phosphate-aspartate transcarbamylase activity in tumors. Cancer Res. 19: 101-104 (1959).

10. Curci, M.R. and Donachie, W.D. : An attempt to find pyrimidine inhibitors of a mammalian aspartate carbamyltransferase. Biochim. biophys. Acta 85: 338-341 (1964).

11. Davidson, J.L. and Leslie, I.: Nucleic acids in relation to tissue growth: a review. Cancer Res. 10: 587-594 (1950).

12. Enesco, M. and Leblond, G.P.: Increase in cell number as a factor in the growth of the organs and tissues of the young rat. J. Embryol. exp. Morph. 10: 530-562 (1962).

13. Gerhart, J. G. and Pardee, A.: The enzymology of control by feedback inhibition. J.biol. Chem. 237: 891-896 (1962).

14. Gerhart, J. C. and Schachman, H.K.: Distinct subunits for the regulation and catalytic activity of aspartate transcarbamylase. Biochemistry 4: 1054-1062 (1965).

15. Hager, S.E. and Jones, M.E.: A glutaminedependent enzyme for the synthesis of carbamyl phosphate for pyrimidine biosynthesis in fetal rat liver. J. biol. Chem. 242: 5674-5680 (1967).

16. Hamburger, V. and Hamilton, H.L.: A series of normal stages in the development of the chick embryo. J. Morph. 88: 49-92 (1951).

17. JonEs, M.E.: Carbamyl phosphate. Science 140: 1373-1379 (1963).

18. Krm, S. and Cohen, P. P.: Transcarbamylase activity in fetal liver and in liver of partially hepatectomized parabiotic rats. Arch. Biochem. 109: 421-428 (1965).

19. Kretchmer, N.; Hurwitz, R. and Galofré, A.: Pyrimidine biosynthesis in mammals during development (Abstract). Pediat. Res. 1: 414 (1967).

20. Kretchmer, N.; Hurwitz, R. and Ralha, N.: Some aspects of urea and pyrimidine metabolism during development. Biol.neonat. 9: 187-196 (1966).

21. Lescie, I. and Davidson, J. N. : The chemical composition of the chick embryonic cell. Biochim. biophys. Acta 7: 413-428 (1951).

22. Lowenstein, J.M. and Cohen, P.P.: Studies on the biosynthesis of carbamylaspartic acid. J.biol. Chem. 220: 57-70 (1956).

23 Lowry, O.H.; Rosebrough, N.J.; FArr, A.L. and RANDALL, R.J.: Protein measurement with the Folin phenol reagent. J.biol. Chem. 193: 265-275 (1951).

24. Maresh, G. G.; Kwan, T.H. and Kalman, S. M.: Carbamyl phosphate synthetase in the chick. Canad.J. Biochem. 47: 61-63 (1969).

25. Neumann, J. and Jones, M. E.: End-product inhibition of aspartate transcarbamylase in various species. Arch. Biochem. 104: 438-447 (1964).

26. Nordmann, Y.; Hurwitz, R. and Kretchmer, N. : Activity of aspartate transcarbamylase in heart 
and liver of the developing rat. Nature, Lond. 201: 616-617 (1964).

27. Prager, M.D.; Young, J.E. and Atkins, I.C.: A study of the possible role of feedback inhibition of aspartate transcarbamylase in regulation of pyrimidine synthesis in human leukocytes. J. Lab. clin. Med. 70: 768-776 (1967).

28. Reichard, P.: The enzymic synthesis of pyrimidines. Adv. Enzymol. 21: 263-294 (1959).

29. Romanoff, A.L.: The avian embryo. Structural and functional development, p. 1149 (Macnillan, New York 1960).

30. Romanoff, A.L.: Biochemistry of the avian embryo. A quantitative analysis of prenatal development, pp. 261-273 (Wiley, New York 1967).

31. Shafritz, D.A. and Sentor, J.R.: Synthesis of pyrimidine nucleotide precursors in human and rat small intestinal mucosa. Biochim. biophys. Acta 141: 332-341 (1967).

32. Sahimke, R.T.: Adaptive characteristics of urea cycle enzymes in the rat. J.biol. Chem. 237: 459468 (1962).

33. Sahneider, W. C.: Phosphorus compounds in animal tissues. I. Extraction and estimation of DNA and RNA. J. biol. Chem. 161: 293-303 (1945).

34. SköLD, O.: Uridine kinase from Ehrlich ascites tumor: purification and properties. J. biol. Chem. 235: 3273-3279 (1960).

35. Sköld, O.: Enzymes of uracil metabolism in tissues with different growth characteristics. Biochim. biophys. Acta 44: 1-12 (1960).

36. Stern, L.L. and Coren, P.P.: Correlation of growth and aspartate transcarbamylase activity in higher plants. Arch. Biochem. 109: 429-433 (1965).

37. Tatibana, M. and Ito, K.: Carbamyl phosphate synthetase of hematopoietic mouse spleen and the control of pyrimidine biosynthesis. Biochem. biophys. Res. Commun. 26: 221-227 (1967).

38. Thibodeau, P.S. and Thayer, S.A.: Effect of pregnancy and hormones on the activity of aspartate transcarbamylase and the level of nucleic acids in the mammary gland of the rat. Endocrinology, Springfield 80: 505-509 (1967).

39. Yates, R.A. and Pardee, A.B.: Control of pyrimidine biosynthesis in Escherichia coli by a feed-back mechanism. J. biol. Chem. 221: 757-770 (1956).

40. Yates, R. A. and Pardee, A. B.: Control by uracil of formation of enzymes required for orotate biosynthesis. J. biol. Chem. 227: 677-692 (1957).
41. Young, J.E.; Prager, M.D. and Atkins, I.C.: Comparative activities of aspartate transcarbamylase in various tissues of the rat. Proc. Soc. exp. Biol. N.Y. 125: 860-862 (1967).

42. Kimber Farms, Niles, GA.

43. Model RC2-B refrigerated centrifuge, Ivan Sorvall, Inc., Norwalk, CT.

44. Gilford Instrument Laboratories, Inc., Oberlin, $\mathrm{OH}$.

45. The radioactive substrates, $D, L-4,5$-dihydroorotic acid-6[ $\left[{ }^{14} \mathrm{C}\right]$ (specific activity, $3.74 \mu \mathrm{Ci} / \mu \mathrm{mole}$ ) and uridine-2[ $\left[{ }^{11} \mathrm{C}\right]$ (specific activity, $30 \mu \mathrm{Ci} / \mu$ mole), were obtained from New England Nuclear Corporation, Boston, MA.

46. Packard Tri-Carb, Packard Instrument Company, Inc., Downers Grove, IL.

47. Model 7201, Packard Instrument Company, Inc., Downers Grove, IL.

48. Obtained from Nutritional Biochemicals Corporation, Cleveland, $\mathrm{OH}$.

49. The calculations utilized for number of nuclei and protein per nucleus were performed according to Enesco and Leblond [12] using the amount of DNA per diploid nucleus in the chick embryo reported by DAvidson and LesLIE [11].

50. Computations were done with the help of Advance Computer for Medical Research (ACME) system.

51. This study was presented in part at the Annual Meeting of the Society for Pediatric Research, Atlantic City, New Jersey, May 1968.

52. The authors express their gratitude to Miss RuTH HuRwitz for her invaluable help throughout this investigation, and also to Mrs. ILSE LOMmER for her technical assistance.

53. Alberto Galofré was a postdoctoral fellow of the W.K. Kellogg Foundation. The present address of Dr. Galofré is : Department of Pediatrics, Hospital Roberto del Rio, Zanartu 1085, Santiago, Chile.

54. Supported in part by a grant from The National Foundation-March of Klimes, and Public Health Service Research Grants nos. HD-49, HD-00391, and HD-02147.

55. Requests for reprints should be addressed to: Norman Kretchmer, M.D., Department of Pediatrics and Human Development, Stanford University School of Medicine, Stanford, CA 94305, USA.

56. Accepted for publication September 9, 1969. 